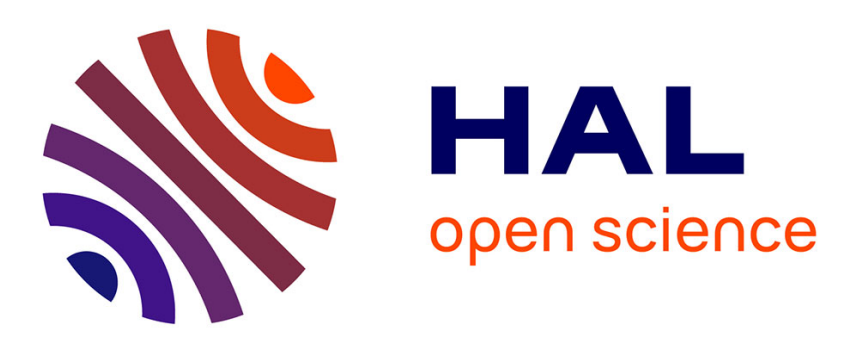

\title{
Influence of the substrate/photo-active solution interaction in patterning and adhesion of photo-deposited films
}

Emmanuel Hugonnot, Marie-Hélène Delville, Jean-Pierre Delville

\section{- To cite this version:}

Emmanuel Hugonnot, Marie-Hélène Delville, Jean-Pierre Delville. Influence of the substrate/photoactive solution interaction in patterning and adhesion of photo-deposited films. Applied Surface Science, 2005, vol. 248 (1-4), pp.479-483. 10.1016/j.apsusc.2005.03.068 . hal-00095271

\section{HAL Id: hal-00095271 \\ https://hal.science/hal-00095271}

Submitted on 15 May 2009

HAL is a multi-disciplinary open access archive for the deposit and dissemination of scientific research documents, whether they are published or not. The documents may come from teaching and research institutions in France or abroad, or from public or private research centers.
L'archive ouverte pluridisciplinaire HAL, est destinée au dépôt et à la diffusion de documents scientifiques de niveau recherche, publiés ou non, émanant des établissements d'enseignement et de recherche français ou étrangers, des laboratoires publics ou privés. 


\title{
Influence of the Substrate/Photoactive Solution Interaction in Patterning and Adhesion of Photodeposited Films
}

\author{
Emmanuel Hugonnot ${ }^{\#}$, Marie-Hélène Delville ${ }^{\dagger}$, and Jean-Pierre Delville ${ }^{\#}$ \\ \#Centre de Physique Moléculaire Optique et Hertzienne, UMR CNRS/Université No.5798, \\ Université Bordeaux I, 351 Cours de la Libération, F-33405 Talence cedex, France \\ ${ }^{\dagger}$ Institut de Chimie de la Matière Condensée de Bordeaux, UPR CNRS No 9048, 87 Avenue \\ du Docteur A. Schweitzer, F-33608 Pessac cedex, France
}

Corresponding author: Jean-Pierre DELVILLE

Centre de Physique Moléculaire Optique et Hertzienne, UMR CNRS/Université No.5798, Université Bordeaux I, 351 Cours de la Libération, F-33405 Talence cedex, France Phone: (33) 5400022 07; Fax: (33) 540006970

Email: jp.delville@cpmoh.u-bordeaux1.fr

\begin{abstract}
Using the photochemical deposition of chromium hydroxide layers driven by a continuous $\mathrm{Ar}^{+}$laser wave in a potassium chromate solution, we explored the adhesion and patterning properties of the induced deposit on glass substrates versus the composition and the $p H$ of the photoactive solution. The experiments were performed with two interfering beams imprinting an optical pattern on the substrate and analyzing the resulting morphology of the deposit. The solubility, patterning and adhesion are investigated using both organic (acetic acid) and inorganic ( $\mathrm{HCl}$ ) acids. The observed adhesion as a function of the $p H$ in the photodeposition process (surface versus bulk) was compared for several substrates.
\end{abstract}


PACS Numbers: 81.15.Fg, 81.10.Dn, 42.40.Eq, 42.70.Gi

Keywords: photochemical deposition, surface patterning, adhesion, laser, chromate

\section{Introduction}

Laser writing has become the corner stone of numerous material processing technologies because surface patterning is performed in situ and in a single step. Among the different laser writing methods, such as photo-electrochemical etching [1], photo-doping [2], laser ablation [3], laser machining [4], or chemical processing with lasers [5], the photochemical deposition of thin films in liquid solutions [6] is especially attractive because it can be applied to a broad range of precursors, including molecular compounds. However, contrary to other techniques, the choice of substrate becomes crucial since the deposit nucleation must occur on the surface instead of bulk, and adhesion between dissimilar materials, e.g. the photodeposit and the substrate, strongly depends on the chemical, physical and morphological properties of the interface. While adhesion is important, it has surprisingly been very poorly discussed for photochemical deposition processes [7]. As precipitation of chromium hydroxide appears in numerous technological areas [8], we investigate its photodeposition characteristics on glass substrates. By varying the composition and the $p H$ of the initial chromate solution, known to affect deposition [9], we compare here in each case the chromium hydroxide solubility, the substrate patterning and adhesion, and discuss the resulting correlation.

\section{Experimental Section}


Experiments are performed at room temperature using two starting acidic liquid mixtures I and II composed of potassium chromate $\operatorname{Cr}(V I)(9 \% \mathrm{wt})$, ethanol (8\% wt), and water. The $p H$ was adjusted using either $1 \mathrm{~N}$ hydrochloric acid for mixture I or $1 \mathrm{~N}$ acetic acid for mixture II. The presence of an organic compound, $R O H$, is necessary as an organic quencher providing electrons towards activated $\operatorname{Cr}(V I)$. Even if the acetic acid plays this role in mixture II, the alcohol enhances the photo-redox process. Our choice for chromate was motivated by the well-known photoreduction of $\operatorname{Cr}(V I)$ ions into $\operatorname{Cr}(I I I)$ used for hologram recording by dichromated gelatins [10]. Photoreduction starts with a light-induced excitation of $\operatorname{Cr}(V I)$ followed by a reduction to intermediate $\operatorname{Cr}(V)$ and a dark reaction from $\operatorname{Cr}(V)$ to $\mathrm{Cr}(\mathrm{III})$, here amorphous $\mathrm{Cr}(\mathrm{OH})_{3}$, given schematically by Eq. (1):

$$
\begin{aligned}
& \operatorname{Cr}(V I)+h v \rightleftharpoons \operatorname{Cr}(V I)^{*}, \\
& \operatorname{Cr}(V I)^{*}+R O H \rightarrow " C r(V)^{\prime \prime} \rightarrow \ldots \rightarrow \operatorname{Cr}(I I I),
\end{aligned}
$$

where $h v$ indicates the energy of the absorbed photon. The photochemical reaction is driven by a linearly polarized $\mathrm{cw} \mathrm{Ar}^{+}$laser with the line $\lambda=514 \mathrm{~nm}$. Solution mixtures are enclosed in tight homemade cells composed of a glass plate and a cover slide separated by mylar spacers $30 \mu \mathrm{m}$ thick. The optical excitation is driven by two interfering beams of beam waist $a_{0}=156 \mu \mathrm{m}$, to cast a fringe pattern of fringe spacing $\Lambda=5 \mu \mathrm{m}$ on the substrate. The adhesion of the photodeposit was investigated by the scotch tape test [11].

\section{Chromium Hydroxide Solubility}


According to the reaction scheme given by Eq. (1), the $\operatorname{Cr}(I I I)$ concentration in the solution is an increasing function of the laser beam power and reaches a steady value during exposure. The nucleation of the $\operatorname{Cr}(I I I)$ precipitate occurs as soon as the concentration reaches the solubility of $\mathrm{Cr}(\mathrm{OH})_{3}$ in the solution. The $\mathrm{pH}$ variations of the solubility threshold for the mixtures I and II are presented in Figure 1. We measure the solubility at a given $\mathrm{pH}$ using a dichotomy procedure in beam power and setting the maximum exposure time to one hour. Since $\mathrm{HCrO}_{4}^{-} \rightleftharpoons \mathrm{CrO}_{4}^{2-}+\mathrm{H}^{+} \quad(p K=6.49)$, where $\mathrm{HCrO}_{4}^{-}$is the hexavalent form of $\mathrm{Cr}(\mathrm{VI})$ activated by the blue-green wavelength range of a $\mathrm{Cw} \mathrm{Ar}^{+}$laser, various forms of $\mathrm{Cr}(\mathrm{VI})$ can be found in aqueous solutions. As the concentration of $\mathrm{HCrO}_{4}^{-}$ decreases for $p H>7$, a significant increase in beam power is expected to produce and precipitate $\mathrm{Cr}(\mathrm{OH})_{3}$. On the other hand, $\mathrm{Cr}(\mathrm{OH})_{3}$ is highly soluble at low $p H$, as shown in the Inset of Figure 1 [12], and large beam powers are also required to reach the solubility.

\section{Adhesion of the Induced Deposit}

Besides the study of the $\mathrm{Cr}(\mathrm{OH})_{3}$ solubility during the laser excitation, we investigated the patterning of the resulting deposit and analyzed its adhesion to the glass substrate. As illustrated in Figure 2, the surface patterns induced by two interfering beams can be different for mixtures with different compositions. The $p H$ dependence of the morphology is also important since surface relief gratings are only deposited at low $p H$. Surprisingly, the beam interference pattern cast on the substrate gives a rough coating at high $p H$. Results for a large variation in $p H$ are summarized in Figure 3. 
When hydrochloric acid is used (mixture I), the deposit is not adherent at low $p H$. In this case, the silica at the interface is of the form $\mathrm{SiOH}_{2}^{+}$. It is thus positively charged, as the $\mathrm{Cr}(\mathrm{III})$ deposit which is of the form $\mathrm{Cr}\left(\mathrm{H}_{2} \mathrm{O}\right)_{6}{ }^{3+} 3 \mathrm{Cl}^{-}$. Moreover, the $\mathrm{Si}-\mathrm{O}-\mathrm{Cr}$ bond has shown to be unstable with respect to $\mathrm{HCl}$ in solution [13]. A thermal treatment of the glass and the $\operatorname{Cr}(\mathrm{III})$ at $200{ }^{\circ} \mathrm{C}$ in vacuum is necessary in order to favour the formation of anchored $\mathrm{Si}-\mathrm{O}-\mathrm{Cr}$ bonds to the surface [14]. For $\mathrm{pH}>2$, the silica at the interface is first neutral with $\mathrm{SiOH}$ bonds. Then, for increasing $p H$, the surface of silica exhibits a decreasing ratio of $\mathrm{SiOH} / \mathrm{SiO}^{-}$becoming more and more negatively charged until the total transition to the form $\mathrm{SiO}^{-}$found around $p H=10$. For the same $p H$ values, the $\mathrm{Cr}(\mathrm{III})$ species is essentially in its neutral form $\mathrm{Cr}(\mathrm{OH})_{3}\left(\mathrm{H}_{2} \mathrm{O}\right)_{3}$. The condensation of this complex leads to the formation of hydrated hydroxide gels. On the other hand, the $\mathrm{O}^{-}$and $\mathrm{OH}$ groups at the silica surface participate in the reaction with the $\mathrm{CrOH}$ leading to the creation of $\mathrm{Si}-\mathrm{O}-\mathrm{Cr}$ molecular bonds. Thus, deposits should adhere to the substrate at intermediate $\mathrm{pH}$, when the $\mathrm{HCl}$ concentration is decreased. We did not see evidence for this expected adhesion up to $p H=4$, whereas the coating partially remained on the substrate between $p H=4$ and 7 . Finally, for higher $p H$, typically $p H>7$, the hydrated chromium hydroxide gel first dissolves and gives $\left[\mathrm{Cr}(\mathrm{OH})_{4}\left(\mathrm{H}_{2} \mathrm{O}\right)_{2}\right]^{-}$species [12]. As the interface is in this case also negatively charged, electrostatic repulsion prevents any adhesion. The same behavior is expected for mixture II with the acetic acid, but the absence of chloride increases the stability of the $\mathrm{Si}-\mathrm{O}-\mathrm{Cr}$ chemical bond and leads to a much better coating adhesion.

The same type of experiments was carried out on other substrates, such as silanized glass, PMMA and Indium tin oxide. If we define as Peled [6] a relative adsorption affinity $\chi_{A}$ towards the substrate, we find: 


$$
\chi_{A}\left(\begin{array}{c}
\text { Silanized Glass, } \\
\text { PMMA }
\end{array}\right)<\chi_{A}(\text { Glass })<\chi_{A}\left(\begin{array}{c}
\text { Indium Tin } \\
\text { Oxide }
\end{array}\right) .
$$

\section{Morphology of the Induced Deposit}

The $p H$ dependent chemical nature of the induced $\operatorname{Cr}(I I I)$ species can be at the origin of the observed difference in the deposits morphology, i.e. wavy pattern versus rough coating. As shown in Figure 2, the $\mathrm{Cr}(\mathrm{OH})_{3}$ film is modulated by the optical intensity distribution at low $\mathrm{pH}$, where the $\operatorname{Cr}(I I I)$ corresponds to a hydrated hydroxide gel. Moreover, the spatial modulation of the deposited film corresponds to the forced fringe spacing $\Lambda$. This suggests that the $\operatorname{Cr}(I I I)$ nucleation mainly occurred at, or close to, the substrate interface. Bulk nucleation is probably a minor process in this case. On the other hand, Figures $2 \mathrm{~b}$ and $2 \mathrm{~d}$ show the formation of a rough coating for large values of the $p H$,

where $\mathrm{Cr}(\mathrm{III})$ is of the form of $\left[\mathrm{Cr}(\mathrm{OH})_{4}\left(\mathrm{H}_{2} \mathrm{O}\right)_{2}\right]^{-}$instead of a hydrated chromium hydroxide gel. Colloid particles are nucleated in this case. The deposits behave as if they have lost the memory of the laser optical pattern, suggesting a bulk nucleation process followed by a deposition on the substrate by diffusion. The mechanism of this surface-to-bulk transition during the nucleation is not well understood since there is also a large crossover regime at intermediate $p H$ where the gel and colloid form of $\operatorname{Cr}(I I I)$ coexist, as illustrated in Figure 2c. Results are summarized in Figure 3.

\section{Conclusion}


We analyzed the adhesion and morphology of chromium hydroxide layers photodeposited on glass substrate versus the composition and the $p H$ of the initial photoactive solution. For increasing $p H$ the deposit morphology switches from a gel film to a compact colloid aggregate, with a crossover regime. The transition suggests that the nucleation of deposits varies from surface- to bulk-controlled for increasing $p H$. Good adhesion to the substrate occurs only at intermediate $p H$. Our investigation shows that maps like those in Figure 3 represent efficient tools to optimize surface patterning driven by photochemical reactions. 


\section{Figures Captions}

Figure 1: Laser beam power required to reach solubility versus $p H$ values for the photoactive mixtures I and II. Inset: Variation of the solubility of chromium hydroxide versus the $p H$ of the solution.

Figure 2: Influence of the $p H$ and the mixture composition on the morphology of the induced deposit. (a) Mixture I with $p H=0.6, P=35 \mathrm{~mW}$ and irradiation time $t_{i r}=150 \mathrm{~s}$. (b) Mixture I with $p H=6.8, P=3.5 \mathrm{~mW}$ and irradiation time $t_{i r}=300 \mathrm{~s}$. (c) Mixture II with $p H=6.2, P=30 \mathrm{~mW}$ and irradiation time $t_{i r}=300 \mathrm{~s}$. (d) Mixture II with $p H=7.2$, $P=30 \mathrm{~mW}$ and irradiation time $t_{i r}=200 \mathrm{~s}$.

Figure 3: Influence of $p H$ on deposit adhesion and morphology for both mixtures I and II. 
Figure 1

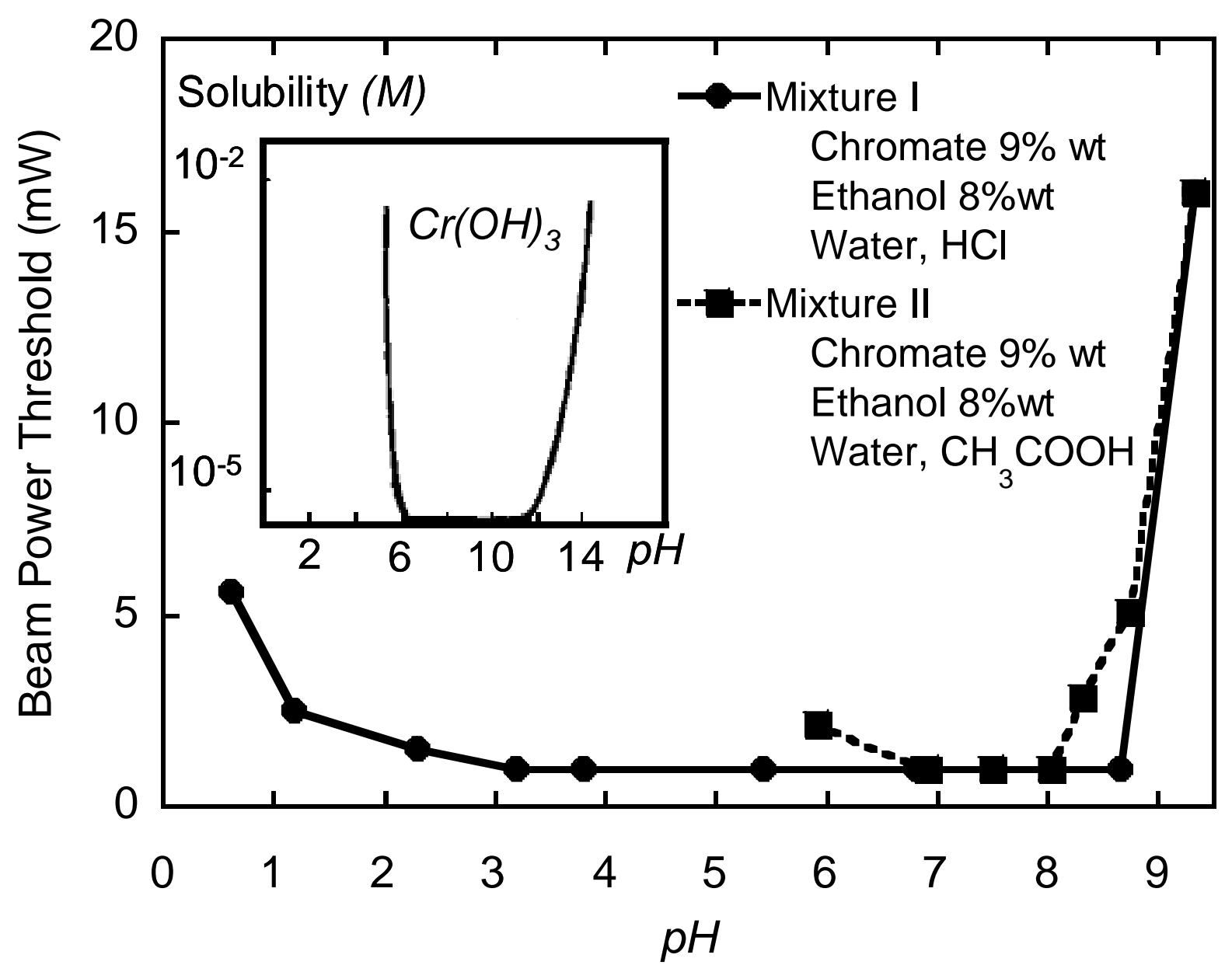


Figure 2
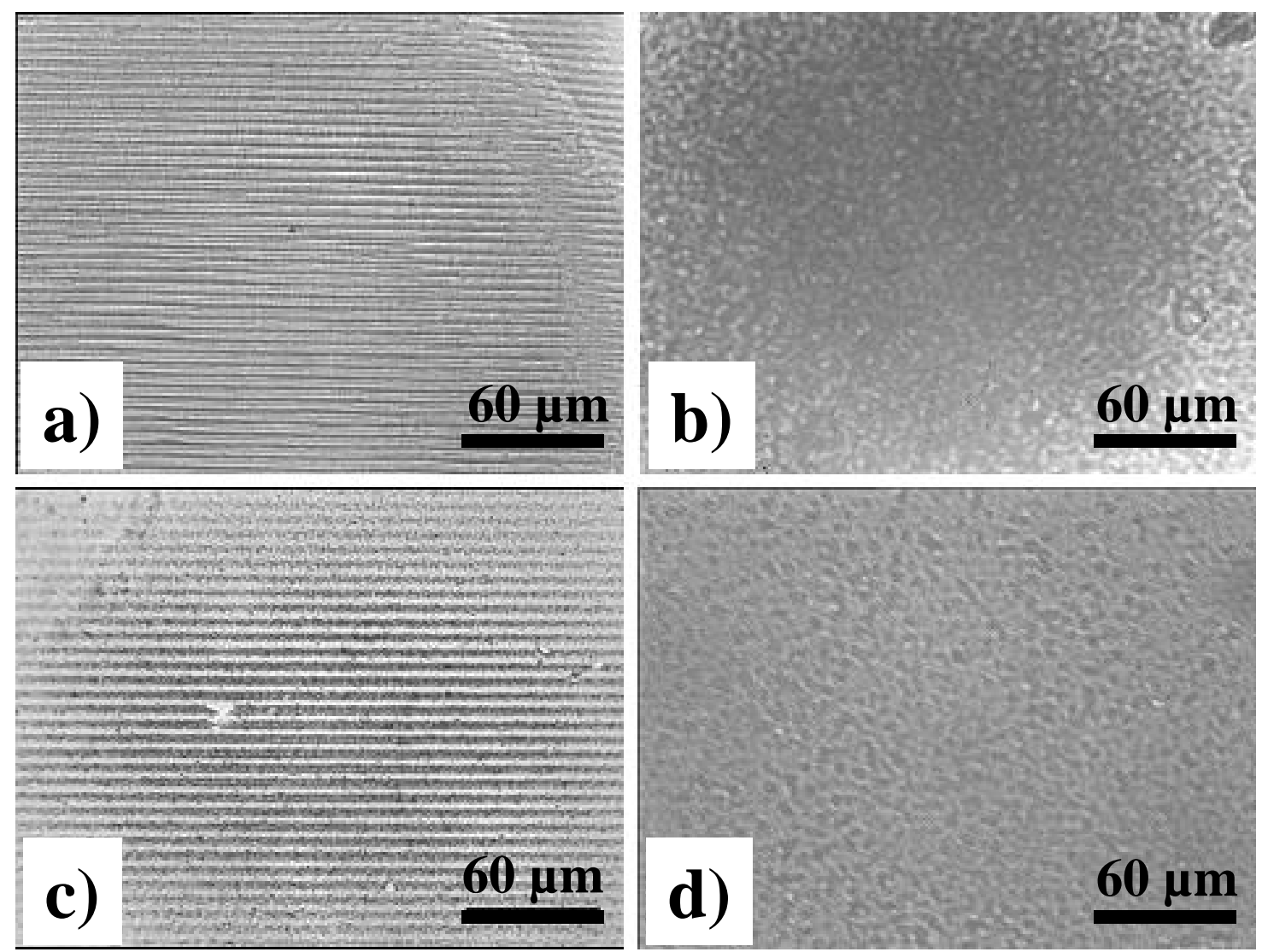
Figure 3a

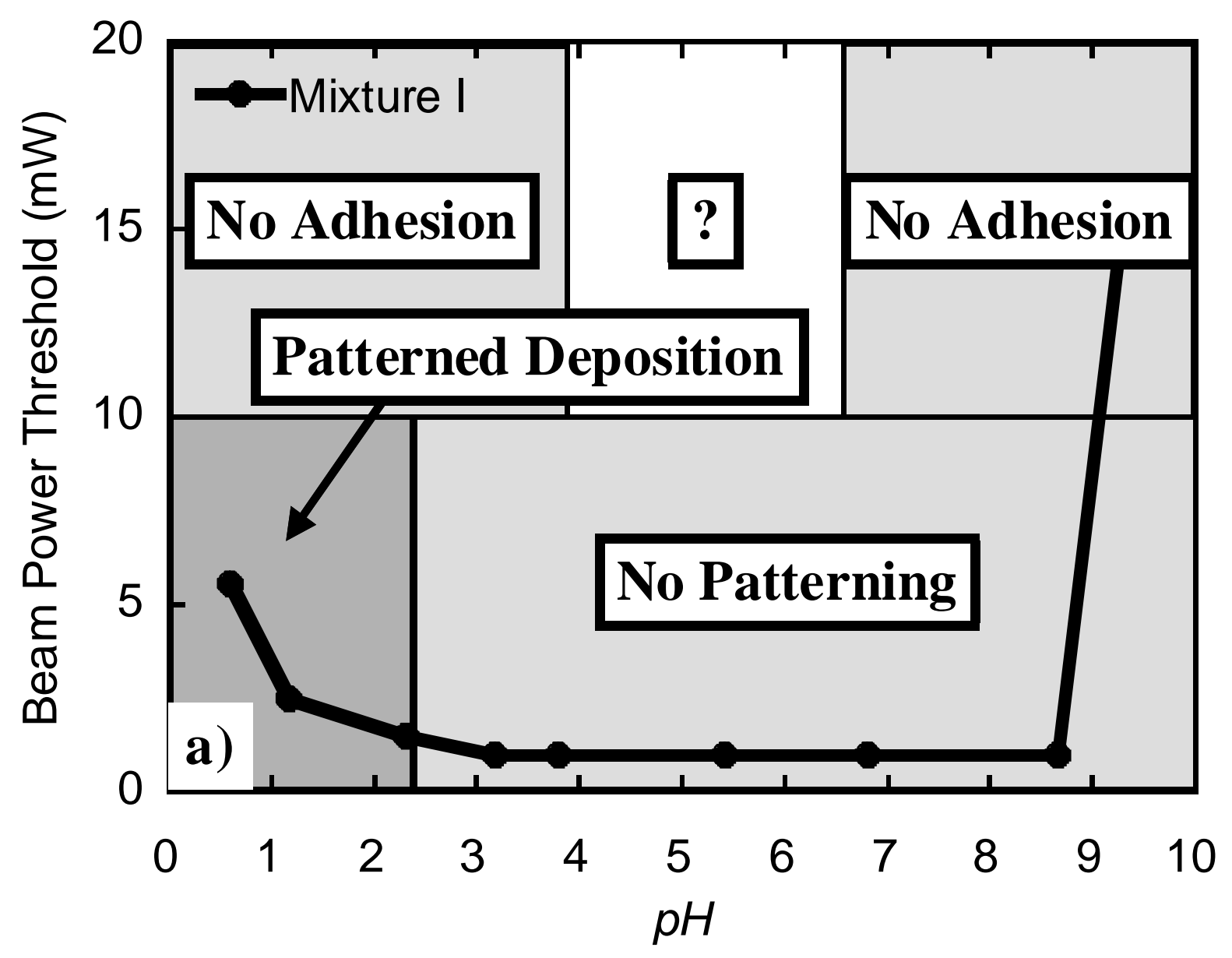


Figure 3b

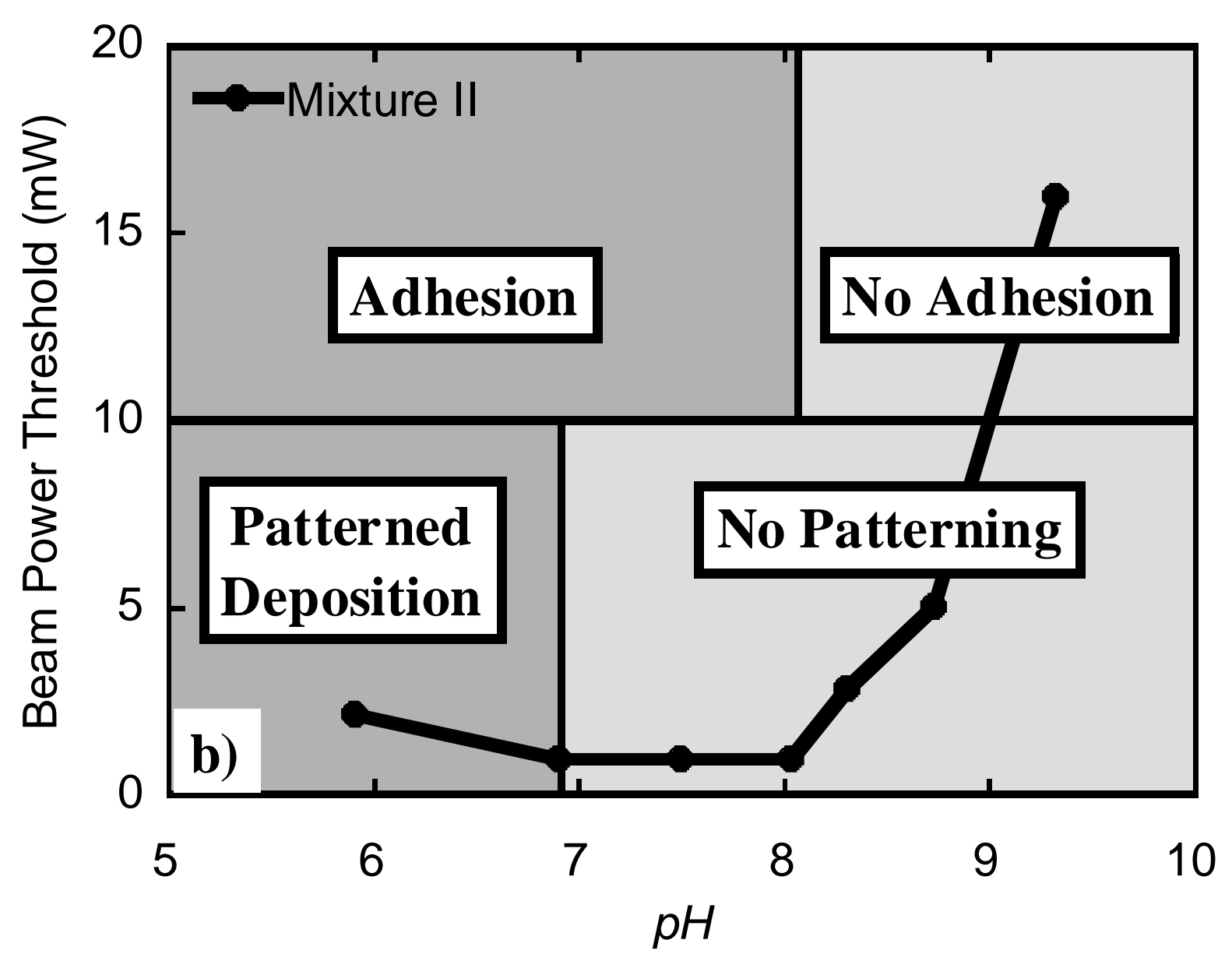




\section{References}

[1] C. I. H. Ashby, Thin Solid Films 218 (1992) 252.

[2] J. Malinowski and A. Buroff, Contemp. Phys. 19 (1978) 99.

[3] J. Dieleman, U. K. P. Bierman, and P. Hess, Guest Editors, Appl. Surf. Sci. 86(1-4) (1995).

[4] D. J. Ehrlich and J. Y. Tsao (Eds), Laser Microfabrication: Thin Film Processes and Lithography (Academic Press, Boston, 1989).

[5] D. Bäuerle, Laser Processing and Chemistry (3rd Edition, Springer, Berlin, 2000).

[6] A. Peled, Lasers Eng. 6 (1997) 41.

[7] V. Weiss, A. Peled, and A. A. Friesem, Thin Sol. Films 218 (1992) 193; A. Peled, A. A. Friesem, and K. Vinokur, Thin Sol. Films 218 (1992) 201.

[8] J. Gómez Morales, J. Garcia Carmona, R. Rodriguez Clemente, and D. Muraviev, Langmuir 19 (2003) 9110.

[9] P. H. Borse, J. M. Yi, J. H. Je, W. L. Tsai, and Y. Hwu, J. Appl. Phys. 95 (2004) 1166.

[10] T. Keinonen and R. Grzymala, Appl. Opt. 38 (1999) 7212; ibid 38 (1999) 7222.

[11] A. A. Avey, and R. H. Hill, J. Am. Chem. Soc. 118 (1996) 237.

[12] J. P. Jolivet, De la Solution à l'Oxyde (CNRS Editions, Paris, 1994).

[13] A. N. Volkova, A. A. Malygin, V. M Smirnov,. S. I. Kol'tsov, and V. B. Aleskovskii, Zhurnal Obshchei Khimii 7 (1972) 42.

[14] S. L. Scott, and J. Amor Nait Ajjou, Chemical Engineering Science 56 (2001) 4155. 